\title{
Tuberculosis, the Canadian Lung Association/Canadian Thoracic Society and the new millennium
}

$\mathrm{T}$ he Canadian Association for the Prevention of Consumption and Other Forms of Tuberculosis, parent to both the Canadian Tuberculosis Association and the Canadian Lung Association (CLA) with its medical arm, the Canadian Thoracic Society (CTS), carried the Cross of Lorraine (Figure 1) and the crusade against tuberculosis (TB) in Canada during the twentieth century. For these societies, the battle was joined long before government - public health and communicable disease control - took up the cause. Allied or unallied with government, these societies were party to no small measure of success. TB mortality was $165 / 100,000$ people in 1908; TB morbidity was just under seven/100,000 people in 1999. Yet, continued success is stalled; the incidence of TB in Canada has not changed for 15 years, and globally, TB is undergoing an unprecedented resurgence. Why is this so, and what of the role of the CLA and CTS in the fight against TB in the new millennium?

The etiological agent of TB, Mycobacterium tuberculosis, has three unique traits. First, its only significant natural reservoir is humans. Second, it has substantially diminished virulence for most animal species other than humans. Finally, it has developed a survival-transmission strategy that is unparalleled among the mycobacteria: airborne human-to-human spread (1). Enabling the survival strategy is the aerobic nature of the species (its growth is favoured in the oxygen- rich environment of the lung), an immunological response that results in liquefaction and lung cavity formation, and a capacity during growth in lung tissue to interrupt perfusion in parallel with ventilation. Any physiological impairment from the disease is accordingly minimized, presentation of the patient is delayed and an opportunity for transmission is created (2).

The medical disease 'tuberculosis' and public health are inseparably linked, or as Osler observed: "TB is a social disease with a medical aspect" (3). Individual and public TB health are best served when TB programs meet two main objectives. The first is the early diagnosis of all infectious (sputum smear-positive) cases, the prompt institution of effective therapy, and the case holding of patients until treatment has been completed and a cure achieved. The second objective is contact investigation and the treatment of latent tuberculous infection in high risk groups. Although effective treatment for TB has been available for 50 years, the disease continues to flourish in most developing countries, and in geographically and demographically distinct groups within developed countries.

In Canada, despite an uninterrupted supply of antituberculous drugs at no charge to the patient, good prescribing practices and, in

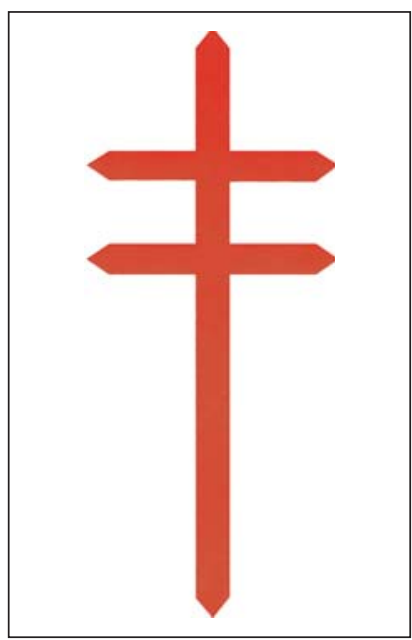

Figure 1) The Cross of Lorraine general, good case holding, the transmission of TB continues to occur among certain minorities such as Canadian aboriginals living on the Prairies or in the Northwest Territories. This is mainly because of delayed diagnosis. In developing countries, many of which are the source of new immigrants to Canada, TB transmission is widespread and common. Often this is because smear-positive cases are not being diagnosed or placed on treatment. An expanded burden of disease because of prevalent human immunodeficiency virus (HIV) infection is overwhelming even the best of these programs. By destroying the two cells most important to the containment of tubercle bacilli (macrophages and $\mathrm{CD}_{4}$ receptorbearing lymphocytes), HIV vigorously promotes the progression of recent or remotely acquired TB infection to active disease.

Drug resistance, on the one hand, is a marker of the effectiveness of a TB control program because naturally occurring resistant mutants evolve when the drug supply is erratic, drugs are poorly prescribed or their delivery to the patient is not secured. On the other hand, drug resistance is a determinant of the success of any existing program and is now increasing in developing countries at an alarming rate. 
Contrary to popular opinion, which judges new drugs to be desperately needed and a valued contribution of industrialized countries to the global anti-TB effort, there is no reason to think that new drug development will be salutary, except in the short term. As long as the preconditions for the selection of drug-resistant mutants prevail, resistance to new drugs can be expected to occur with a high degree of certainty. Furthermore, the cost of drug development is now so large as to inhibit pharmaceutical research.

In truth, in the chemotherapeutic era, TB's continued survival among us is increasingly a reflection of poverty (poor housing, overcrowding and malnutrition), the gross inadequacy of the resources available to TB programs in many developing countries, or occasionally, where resources are adequate, maladministration, corruption, whimsy and shortsightedness. Drug resistance may be simply a reassertion of this truth; by failing to 'right' the socioeconomic and political 'wrong' that causes programs to fail, the disease has returned to us, in immigrants, in resistant forms. In the worst examples of multidrug-resistant $\mathrm{TB}$, progress has been set back 50 years to a time when there was no effective treatment. Ultimately, "emphasis must shift away from the tubercle bacillus as the cause of TB towards societal and political factors that generate poverty, inequity and injustice" (4). To redress the socioeconomic imbalance and to provide a focus of advocacy, the World Health Organization is promoting its 'Stop TB - use Directly Observed Therapy Short Course (DOTS)' campaign, based on a five-point strategy (5) that calls for government commitment to national tuberculosis programs, regular supplies of drugs, effective diagnostic microscopy services, treatment given under direct observation by trained supervisors and audit of the efficacy of the strategy.

Although the CLA/CTS has had an ongoing commitment to TB education and clinical standards in Canada (a fifth edition of Canadian Tuberculosis Standards will be published this year) they have latterly expressed a keen interest in international TB control. This is entirely appropriate. An increasing proportion, now greater than $60 \%$, of all TB patients in Canada are foreign-born, and without better global TB control, there can be no prospect of TB 'elimination' in Canada.
Obvious activities of interest include the continued raising of public awareness and funds to support the following:

- The International Union Against Tuberculosis and Lung Disease. This organization has international status and experience, and has demonstrated its staying power despite chronic underfunding.

- Physician and/or nurse exchange programs, provided there is official confirmation of a commitment to employ that individual in their TB program and that such a program exists.

- Courses for groups from developing countries, with assistance for attendees who are unable to afford the cost.

- Expert review of a country's TB control program.

However, considering the remarkable success of the CLA/CTS in Canada and given the limited resources of national TB programs in many developing countries, possibly the greatest service the CLA/CTS could render international TB control would be to export its model of public advocacy, the marshalling of nongovernmental resources and the establishment of linkages to governmental programs.

Richard Long, MD Chair, Tuberculosis Committee Canadian Thoracic Society

ACKNOWLEDGEMENTS: The author is very grateful to Dr Ted Allen for his helpful comments, and to Sheila Roth and Susan Falconer for their preparation of the manuscript.

\section{REFERENCES}

1. Iseman MD. Evolution of drug-resistant tuberculosis: A tale of two species. Proc Natl Acad Sci 1994;91:2428-9.

2. Long R, Maycher B, Dhar A, Manfreda J, Hershfield E, Anthonisen N. Pulmonary tuberculosis treated with directly observed therapy. Serial changes in lung structure and function. Chest 1998;113:933-43.

3. Grzybowski S, Allen EA. Tuberculosis: A history of the disease in Canada. CMAJ 1999; 160:1025-8.

4. Grange JM, Sumla A. Paradox of the global emergence of tuberculosis. Lancet 1999;353:996.

5. World Health Organization. WHO report on the tuberculosis epidemic. Geneva: WHO, 1997. 


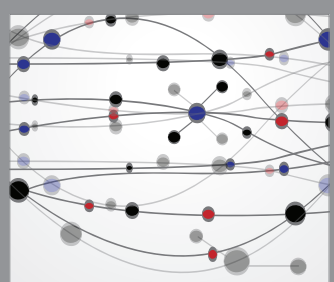

The Scientific World Journal
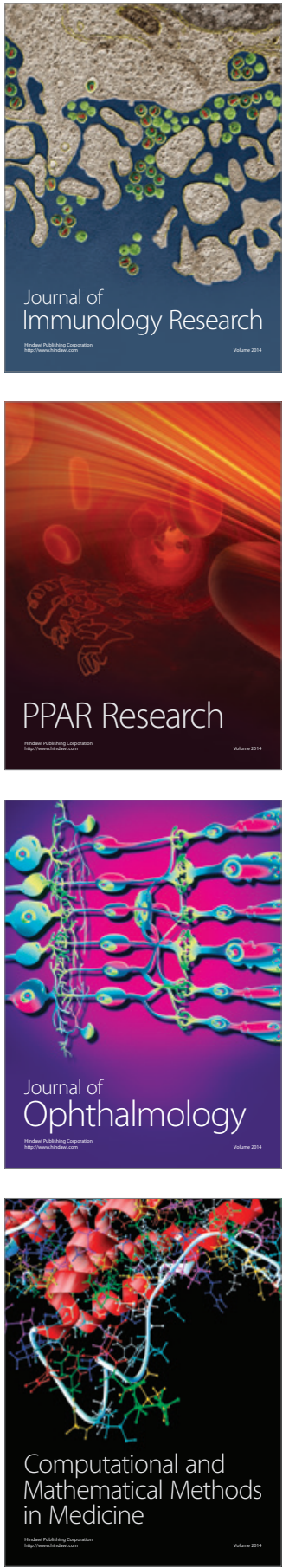

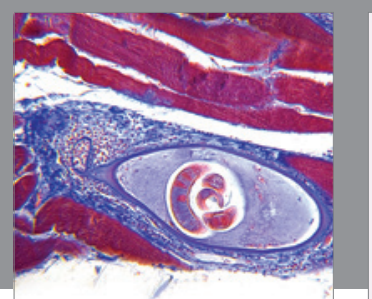

Gastroenterology Research and Practice

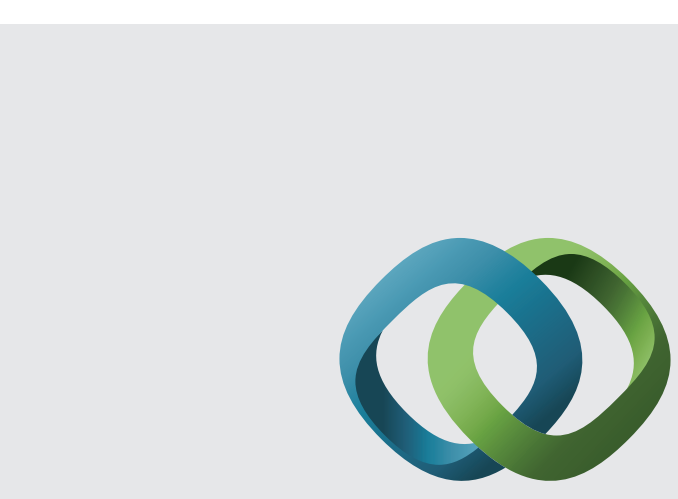

\section{Hindawi}

Submit your manuscripts at

http://www.hindawi.com
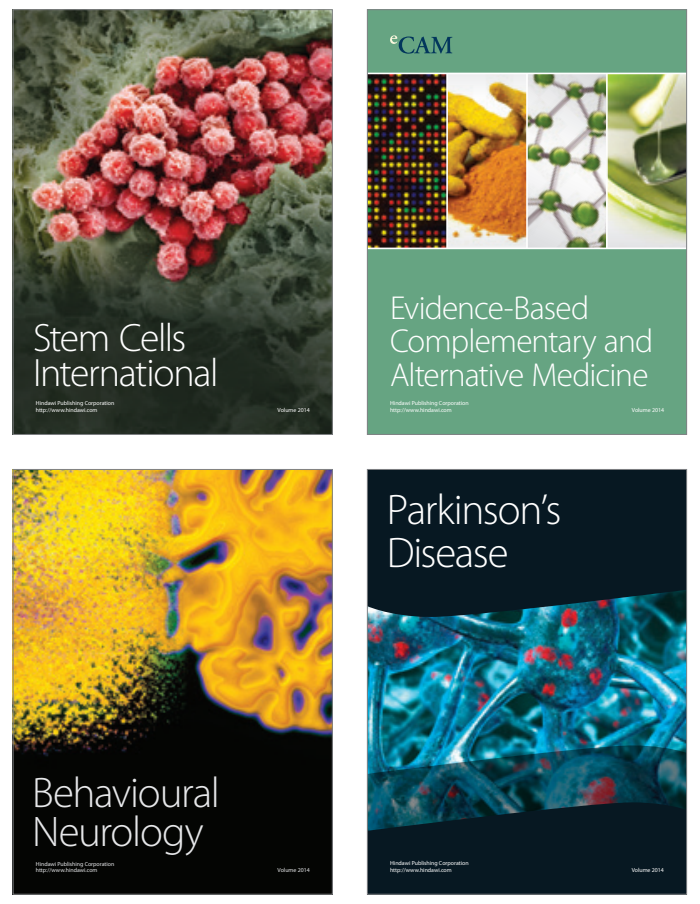
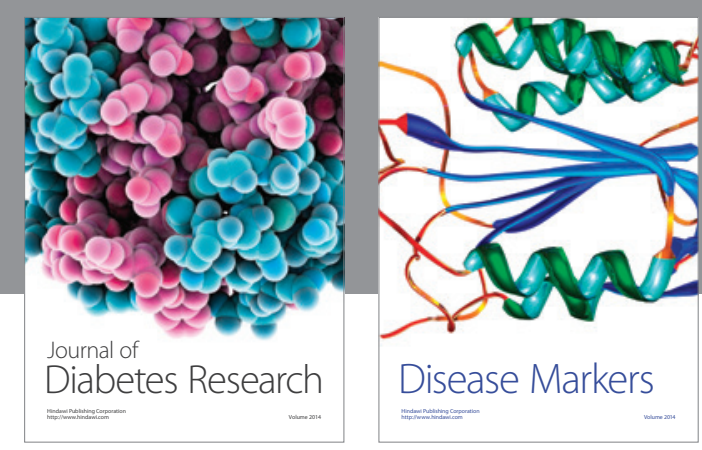

Disease Markers
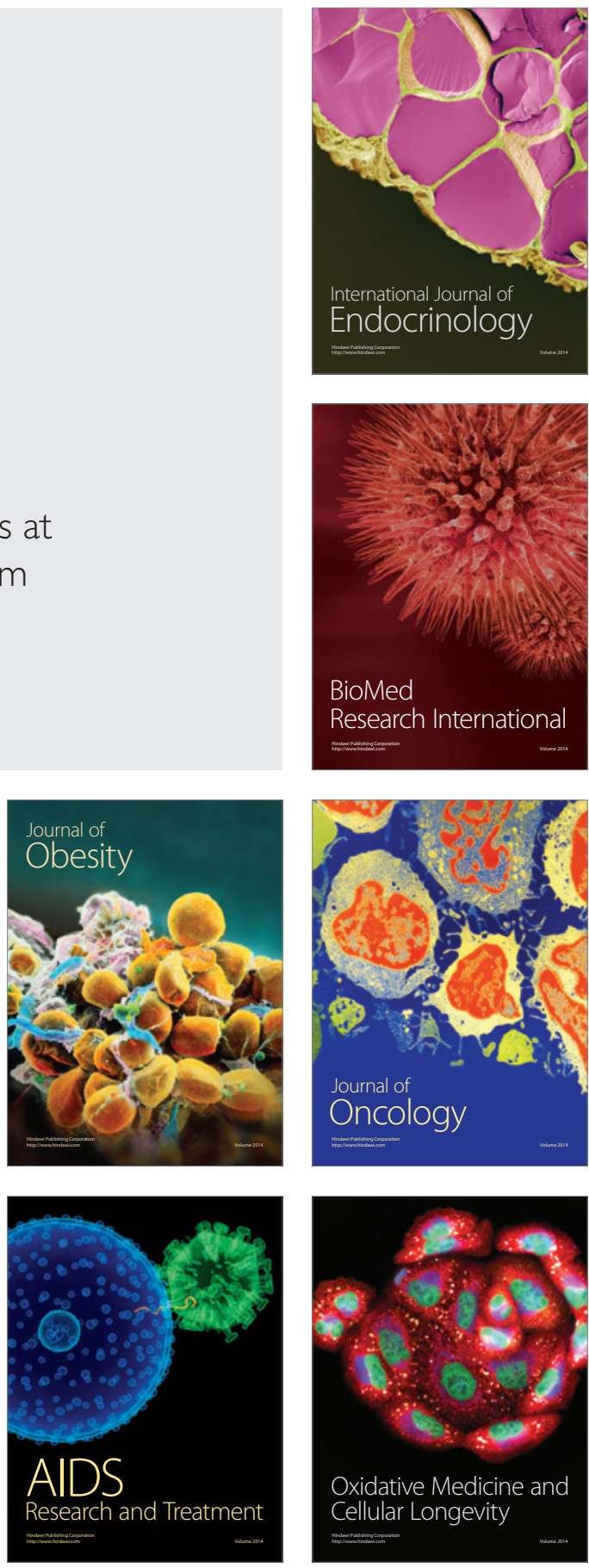